should not usually be a nerve-stretching, as advised by Nussbaum, Horsley, Bowlby, Underwood and Ross, instead of a neurectomy, since the repetitions can just as easily be made, if required. In the case of the inferior dental nerve the first operation can be performed from within the mouth, and thus avoid a visible scar. Operations on the supraorbital and the infraorbital trunks require moderate external incisions.

For the purposes of this article we may divide the obstinate trigeminal neuralgia into three groups:

I. Those where the peripheral extremities of a nerve, or portions of the trunk not inaccessibly deep, are the seat of inflammation, pressure, or other forms of irritation. These cases are rare, but they can be positively and permanently cured by neurectomy, and can be relieved at least by nerve-stretching; operating, of course, between the seat of irritation and the brain.

2. Where the inflammation has already passed along the nerve and reached the semilunar ganglion, or at least pretty near it, or where these deeper parts are primarily irritated from various causes. In these cases, and they are the majority apparently, we cannot cut nor stretch between the diseased part and the brain, but we can stretch the nerve, or remove it by avulsion, or excise a piece of it at no great distance from the inflamed ganglion itself. A nerve-stretching here acts mechanically to some extent upon the substance of the ganglion itself, bringing immense relief, and sometimes permanent cure, to the patient. It is also the opinion of neurologists that by cutting off the irritating external impressions from reaching the diseased part, we give them a prolonged "physiological rest" and strongly favor recovery.

3. Where the seat of irritation is in the brain or medulla oblongata, or in the nerve between the medulla and the semilunar ganglion, but not in the ganglion itself, we are unable to exert any direct mechanical force upon it, but the operations may still be curative by cutting off the reception of irritating external impressions and obtaining for the diseased part of the cerebrum the physiological rest already mentioned.

My conclusion is that repeated operations at the same point are of great value in relapsing cases, that they are not dangerous nor exhausting, and afford a patient a relief which, by some repetitions, will often make him entirely comfortable for the remainder of his lifetime.

No. 6 Sixteenth St., Chicago.

To Calculate the Capacity of Cisterns. -A correspondent of the Scientific American gives the following rule for calculating the capacity of a cistern :

Rule.-Square the diameter of cylinder in inches, and multiply by $0.0408=$ gallons per foot.
HEART STRAIN AND WEAK HEARTS. Read before the American Climatological Sociely, Washington, $D . C$,
September $21,1888$.

BY JAMES J. LEVICK, M.D., OF PHILADELPHA.

In the remarks I am about to offer I have put together a few facts and notices of cases coming under my immediate care or notice. The subject is one which has already claimed considerable attention. Were I to give a bibliography, I should name among those who have written on this subject the President of this Society, Dr. Loomis; Drs. Robinson, Kelly, DaCosta, Delafield, Chew and others.

I became, myself, first personally acquainted with the morbid condition referred to, in my early manhood, in a hurried walk up Mount Washington. This required hard climbing, as any one who attempts its ascent on foot will find. Long before I reached the summit I was conscious of an oppression in breathing, a want of breath in fact, and a distressing ache of the heart, which made me regret the venture. From that day to this I have never made the ascent of a mountain of any considerable height without a reminder of this occurrence, A similar experience is recorded by Dr. Clifford Albutt, and by mountain climbers in the Tyrol, and elsewhere. That a strain of the heart made in this way, or by any other modes of excessive muscular action, even in early life, may leave its effects for years, I have not a doubt.

Hence, I am not enthusiastic when I read of the tremendous strain brought on the heart of the successful oarsman in his last "spurt," by the champion lifter of many hundreds of pounds, or by the prize taker in the run of so many miles. Nor do I at all sympathize with the craze for climbing mountains, in which so many young men and women indulge.

It is true that in these young athletes the heart and its adjacent tissues are much better able to bear and more readily to recover from the strain than they are later in life, but that, even with them, a permanent injury may be received, I well know,

I have no better name to offer for this morbid condition than that of heart strain, nor can I apply to the condition which follows the oft repeated occurrence of these phenomena any title more descriptive than that of weak heart.

There is indeed a weak heart occurring in the course of, or as a sequence of, acute disease, very different from that to which I refer. It is a condition which we cannot be too vigilant in watching for, or better; in guarding against. It is notoriously frequent in the parturient woman after an exhausting labor, it is one of the most frequent sequelæ of diphtheria, but it is also not unfrequently a concomitant of pneumonia and of typhoid fever, and I suspect many of us can re- 
call cases in which, after the patient has seemingly passed successfully through these diseases, a fatal result has followed the undue taxing of the heart by the patient too early assuming the erect position.

But the weak heart to which I refer comes on gradually, and after repeated strain, sometimes without obvious cause, though such cases are often associated with a gouty diathesis. More frequently a careful investigation will show that nervous causes, emotional in their nature, and especially those of a depressing character, loss of fortune, or of good name, the misconduct and disgrace of children, have been followed by this heart ache. Now, the slightest unusual exertion, the simplest emotion will bring on an attack, and the temporary stasis of blood in the heart favors the gradual distension, dilatation and weakening of the heart itself. And yet this dilatation is rarely such as to develop cardiac murmurs. I have known many more sudden deaths to occur from heart trouble, where there was no appreciable murmur, than where there was one. Given, then, the absence of cardiac murmurs, the presence of heart ache, oppression in breathing on rapid exertion, going on to dyspncea, though rarely the dyspncea of valvular disease, with pain in the epigastrium rather than in the hypochondrium, with eructation of gas, coming on later, and affording relief, and we have symptoms which have long been grouped together under the title of "Angina Pectoris," the diagnosis of which would seem to be of the simplest character. And yet the early detection of the nature of these phenomena, so amenable to treatment early, so resisting later, is often neglected. In the first place, the pain is almost always referred by the patient to the epigastrium and regarded by him as a disorder of the stomach. This is confirmed if there be, as there almost always are, eructations of gas, giving relief to the patient. It is a case of dyspepsia, or of "bilious" disorder, and for a long time is treated as such. No lesson should be more early and more emphatically impressed on the mind of the young physician than that he be not misled as to the real seat or cause of the pain by the place or position to which the patient refers it. Many a case of thoracic disease, pleurisy, pneumonia and cardiac trouble, has at first escaped detection because the patient, especially if he be a child, has pointed to the epigastrium or the abdomen as the seat of pain. Nor should the absence of the historic pain down the left arm mislead. It is not an essential symptom, especial$1 y$ in the early stages or milder forms of this malady. Unless properly treated and early, the symptoms which have been enumerated become more and more aggravated, and death suddenly occurs. In cases of sudden death occurring to patients thus affected, under my own care or notice, the following appear to have been the imme- diate exciting causes of death. They are noted here that persons thus affected may avoid them. First. Walking on slippery, icy pavements on a cold day. The patient had walked three or four street blocks to church, and died soon after taking his seat there.

Second. Hurrying to railway station immediately after eating a hearty meal.

Third. Driving for some miles a hard-mouth horse.

Fourth. Riding a hard-mouth horse. This patient had been helped by gentle horseback riding.

Fifth. Sazving off the limb of a tree in his own park. The limb required some effort to reach, the position was a constrained one. This gentleman had had frequent attacks of this disease-a feeble heart. $\bar{A}$ violent paroxysm followed this exertion, and he died before medical aid could be obtained.

Sixth. Hurrying from one steamboat to another, carrying at the same time a heavy hand-bag. Seventh. Assisting to carry a trunk from the railway van to the station.

Eighth. Shovelling coal into the furnace in the cellar.

Ninth. The act of sexual intercourse. Three cases of this kind have recently come under my notice. In the first, a married man, æt. 65 , a violent paroxysm of cardiac pain, immediately followed this act. The patient lived for more than six months, was liable to severe paroxysms of dyspnœa-which he never had before-and died suddenly as he arose from his tea-table. A post-mortem examination showed the absence of valvular disease, but the existence of a firm fibrinous clot in the ventricle, which was evidently ante-mortem, and which doubtless was formed coincidently with the first severe paroxysm, six months before.

And this leads me to say that I have no doubt coagula, thrombi, and heart-clots not unfrequently form in a prolonged paroxysm of this kind, The second case was that of a gentleman æt. 72 , single, and remarkably hale and vigorous for his years, but who had at long intervals attacks of heart pain. After a morning drive, his coachman driving, he "visited"-I use his own words-"a lady and committed venery." He was almost immediately seized with an intense pain near the heart, but managed to walk home, a short distance, and I found him there with a cold skin, very feeble pulse, although he walked forward to receive me. He was immediately put under treatment, but death rapidly supervened. A somewhat similar case is reported of a judge of the Nottingham assizes, who was induced to go home with a young woman of the town, who testified before the coroner that immediately after having had intercourse with her, he turned on his side, gave a groan and died. I have recently seen in con- 
sultation a fatal case of heart failure in a elderly -and if the patient be a good sailor, the happiman, where the history of the case pointed to est results may be expected from an ocean voythis as the cause of death.

A careful examination into the history of this form of heart trouble leaves no doubt on my mind that it occurs more frequently in cold than it does in warm climates.

It is very frequent with us of the Northern and Middle States. It is appallingly frequent in England with its cold, wet and depressing climate, and especially so among the more intellectual classes, and as I have already said is, I believe, often developed in early life by boat racing, which, becoming now so general with us, has for generations been the practice in the English universities,

While I have no doubt that the direct influence of cold, is a large factor in the development of this morbid condition, the easy, careless, indolent life which a warm climate induces may have much to do with its rarity among the Southern people.

Intense cold, occurring periodically, not only predisposes to this condition, but also invites the paroxysm. The terrible blizzard of last winter proved directly fatal to many subjects of this malady, and laid the foundation of the disease in others who from lack of railway conveniences were, to reach their homes, compelled to battle with wind and snow as they never before had done. So thoroughly convinced was the late Dr. Ludlow, of Philadelphia, that cold was an exciting cause of these attacks of heart pain, that he proposed to call the fatal cases occurring in winter cases of cold stroke as opposed to heat or sun stroke of the summer.

Alive then to the predisposing and exciting causes of this malady the treatment becomes a simple, though not always a successful one. And yet, early detected-not misled by the supposed seat of pain and regarded as a gastric disorderthe patient will derive great benefit, first by the simple avoidance of exciting causes, and secondly by a change of climate.

I know of no place in this part of the country, equal, in the summer time, to that of the Adirondacks of Northern New York. The late Dr. Ely, of Rochester, who suffered in this way, has told me that he found great relief at Saranac Lake, and I have known others much helped at St. Regis. I do not mean by naming these mountainous regions to advise the climbing of mountains as recommended by Oertler,' but in this delicious atmosphere an amount of exercise may be taken, even gentle pulling with the oar which could not be borne elsewhere.

Next to this, if there be no valvular diseaseand the two conditions are sometimes associated

If I understand the treatment proposed by Oertler, it is not all intended for the class of cases we are considering, but is rather a system of well regulated diet and exercise admirably suited to the obese, beer drinking people of Central Errope.

age and foreign travel. But, before the patient starts on this voyage, a solemn compact must be made with his physician that he will not hurry for trains or carry hand luggage, a practice much more common in England than it is here.

In the English Channel islands, the Isle of Wight, Jersey, and especially in Guernsey, he will find beautiful scenery, a balmy, healthful atmosphere, the comforts of home, and, in Guernsey, at extraordinary little cost. I believe by such a course of treatment, early adopted, and, as has been said, by the avoidance of exciting causes, this condition of the heart may be greatly helped, if not entirely cured, and this, too, without the use of drugs, or, if any, those of the simplest character.

Next in value to a change of climate and moderate exercise in a favorable environment, I believe most benefit will be derived from the prolonged use of moderate doses of nux vomica, five drops of the officinal tincture three or four times daily, either with or without the compound tincture of gentian. Nitro-glycerine has been strongly recommended, and doubtless has its value, though it has more than once disappointed me. At the recent meeting of the British Medical Association, held in Glasgow, a paper was read on The Cactus Grandiflora, which, in tincture, was recommended as especially suited to this condition of the heart, and as free from any of the objections which apply to digitalis, strophanthus, and to convallaria. This remedy had previously been recommended by Rubini and others. In a violent paroxysm of heart pain, I think we shall all agree that nothing is so promptly effective and, judiciously used, so free from danger as is the inhalation of a few drops of nitrite of amyl-a much safer remedy for a feeble heart than is the hypodermic injection of morphia, from which I have known fatal results. Digitalis, as a remedy for this and other forms of cardiac trouble, has been largely used, and in expressing my estimate of its value I shall probably differ from some of those who hear me, Until within about twenty years ago or more, it was universally taught that digitalis was "a heart sedative;" that, in its long-continued use, a cumulative effect was induced, which, if not carefully watched, was liable to be followed by fatal consequences. Suddenly there came the announcement that all this was an error, that physiological experiments had shown digitalis to be a heart tonic, and that the cumulative action of digitalis was a delusion, if not a snare. And then came the natural rebound from the old caution, and a generation of physicians has grown up, who, regarding it solely as a heart stimulant, use it with a freedom-I had almost said a recklessness - which I honestly believe is a most pernicious practice, and against which I wish to enter an 
earnest protest. There is no form of heart weakness in which it has not of late been used, whether it be the chronic form of heart-failure which has been spoken of, the paralyzed heart of diphtheria and other acute diseases, nay, I have even known it administered to a poor, parturient woman bleeding to death from placenta prævia whose failing heart it was proposed to stimulate, not by brandy, ammonia, and such well-known remedies, but by -digitalis!

Whether, then, digitalis be a heart sedative or a heart tonic, and I believe under certain circumstances it may be one or both, it is a medicine which requires judgment in its use. It is not to be administered merely because the patient has a weak heart. It should never be used until careful ausculation has revealed the condition of the mitral, aortic and other orifices. If we accept the teachings of modern physiology that it gives increased power to the heart, we are bound to accept the same authority that, by contracting the arterioles, it increases also the resistance to the exit of the blood from the heart. If we accept the unmistakable authority of long, practical experience we must admit that cases of sudden death not unfrequently occur to patients using digitalis whose death could not be referred to heart disease alone. Such cases teach us that if digitalis be used the dose must be a small one if the patient be walking about, that its effect on the pulse must be closely watched, and that if the dose be increased the patient must strictly keep the recumbent posture. They also teach that in sudden failure of heart power digitalis is a doubtful if not a pernicious measure; that it is never to take the place of ammonia, brandy, oxygen and other well-known stimulants. In a word-in the hygienic measures which have been named, in the avoidance of exciting causes, in iron, and especially in nux vomica, we have remedies more certain in their effects, more free from danger than is digitalis.

I am indeed quite disposed to believe that in the morbid condition we have been considering, it would be better to dismiss from our practice those medicines which are supposed to act directly on the heart and to content ourselves with those remedies which act by improving nutrition and giving tone to the general system. For, after all, it is not the heart tissue which is alone affected, or which is the most important factor of the disease. Rather is this to be found in those structures which preside over its innervation, nutrition and function-those great ganglionic centres, of which we say so much, but know so little-which are indeed the Huguenots of pathology, to which everything that is obscure or undetermined in the ancestry of disease is with such complacency and self-satisfaction attributed.

Join the Association.

\section{A CASE OF TYPHOID FEVER TREATED} WITH SALOL,--WITH REMARKS.

BY R. H. DAY, M.D.,

OF BATON ROUGE, LA. EX-PRESIDENT OF THE LOUISIANA STATE IIEDICAL SOCIETY, AND PERMANENT MEMBER OF THE AMERICAN MEISICAL ASSOCIATION.

Willie Thomas, colored, æt. I 7 years, was taken sick on Monday, October 22, I888, was brought home on Friday, the 26 th, and on Monday morning, the 29 th, I was called to see him.

The following conditions were noted: Skin hot, dry and pungent, pulse i Io, temperature I02. $4^{\circ} \mathrm{F}$., respiration not counted. Tongue red, parched and deeply fissured, with sordes collected upon front teeth and lips, low muttering delirium, urine scanty and high colored, stools not very frequent, but small, watery, and offensive; abdomen slightly tympanitic and sore upon pressure. This boy, residing in Baton Rouge, had gone to work on a sugar plantation, necessitating hard work, loss of rest, rough living, and considerable exposure ; and a week of cool rainy weather during the time greatly intensified these unsanitary conditions. This sickness was ushered in with a slight chill, succeeded by high fever, which was said to have been continuous up to the time of my visit, the ninth day of his sickness; but I suppose there had been slight morning remissions, since at my evening visit of this day I found his temperature up to $105^{\circ} \mathrm{F}$. and his pulse 130 .

I had no difficulty in diagnosing this as a typical case of typhoid fever-not typho-malarial, but typhoid, ab initio and per se, induced by the cold and wet to which he had been exposed, with loss of rest at night, and the other unsanitary conditions to which he had been subjected. There may have been some local potent factor, other than those mentioned, but if so, I have not been able to make the positive discovery.

At my first visit I made the following prescription :

R. Hydrar. chlor. mitis. . . . . . . grs. $\mathrm{xx}$

Pulv. ipecac, pulv. opii . . . . a grs. . iij

Pulv nitras potass. . . . grs, $x \times x$

nil. Divide into six powders.

S.-Give one every two hours; also applied over the abdomen a warm flax seed meal poultice, with peach tree leaves incorporated with it.

In the evening of same day, when I saw him, he had taken five of the powders, which I then discontinued, and prescribed ro grs. of quinine, with 2 grs. antifebrin in combination, every four hours. Up to my visit next morning, 3oth, he had taken four doses with no obvious effect whatever, his temperature being up to $103^{\circ} \mathrm{F}$., and his general condition, if possible, more threatening. Satisfied that quinine would be useless, and realizing the extreme gravity of the case, and its certain tedious progress, even should a fatal result be averted, I determined to give salol a trial, a drug that has recently gained some favor with the profession in cases involving irritation and in- 